\title{
Intervenção Precoce na Criança com Baixa Visão
}

\author{
Heloisa G. R. Gardon Gagliardo \\ Maria Inês R. S. Nobre ${ }^{2}$
}

\begin{abstract}
RESUM 0
O presente trabalho discute o desenvolvimento da visão considerando os fatores ambientais e de maturação neurológica. Contempla as características do desenvolvimento de crianças com baixa visão e as diferentes áreas do desenvolvimento que podem ser comprometidas pelas alterações visuais. Apresenta uma abordagem da atuação da terapia ocupacional em intervenção precoce, relacionando os pressupostos fundamentais para intervenção nessas crianças.
\end{abstract}

Unitermos: Baixa visão, intervenção precoce, terapia ocupacional.

\section{Introdução}

A intervenção precoce relaciona-se de forma íntima com a prevenção e a detecção precoces. Para Temporini e Kara-José ${ }^{1}$, em se tratando de prevenção de problemas oftalmológicos, tão importante quanto prevenir o aparecimento de doenças, distúrbios ou agravos, é minimizar as suas consequiências.

Considerando a importância que tem a visão para o desenvolvimento da criança, Botega \& Gagliardo ${ }^{2}$ destacam que a intervenção precoce é um recurso precioso para o desenvolvimento da criança com baixa visão.

No que se refere à importância da visão para o desenvolvimento humano, Sanchez ${ }^{3}$ refere que a visão rapidamente unifica as diferentes sensações e põe em relação um sentido com o outro. A visão tem, portanto, como uma de suas principais características, ajudar a integrar as diferentes modalidades sensoriais e auxiliar na compreensão das várias informações que recebemos dos sentidos.

Sabe-se que quando a deficiência visual é diagnosticada no primeiro ano de vida e a criança recebe estimulação prontamente, obtêm-se melhores repercussões na eficiência visual e, conseqüentemente, em todos os aspectos do desenvolvimento.
Nesse sentido, Sonksen et al. ${ }^{4}$ enfatizam a importância do diagnóstico precoce, pois os melhores resultados são obtidos quando a intervenção ocorre no primeiro ano de vida. Do mesmo modo, Gagliardo e Gonçalves ${ }^{5}$ referem que o diagnóstico precoce de qualquer alteração no desenvolvimento da criança favorece sua rápida habilitação, possibilitando um melhor prognóstico.

Sendo a intervenção precoce consequiência do diagnóstico precoce, ela só ocorrerá se houver orientação da família e pronto encaminhamento da criança a serviços de habilitação infantil. Ressalta-se, aqui, a relevância do papel dos profissionais da área médica quanto ao diagnóstico precoce, à orientação da família, ao encaminhamento da criança para habilitação e ao contínuo seguimento do caso.

A intervenção precoce é um processo que se estabelece com a parceria entre médicos, terapeutas e a família. A relação de confiança estabelecida desde os primeiros contatos firma a base para a habilitação da criança.

Intervir precocemente requer profundo conhecimento sobre o processo de desenvolvimento humano, mais especificamente sobre o processo de desenvolvimento da criança e dos fatores que nele interferem. Além disso, a habilitação de crianças

\footnotetext{
Doutoranda em Ciências Médicas - Neurologia - FCM/Unicamp. Terapeuta Ocupacional no CEPRE-FCM-Unicamp.

Doutoranda em Ciências Médicas - Oftalmologia - FCM/Unicamp. Terapeuta Ocupacional no CEPRE-FCM-Unicamp.
} 
deficientes visuais requer compreensão das limitações visuais e, sobretudo, das capacidades visuais dessas crianças e possibilidades de desenvolvimento da eficiência da visão.

Sendo a visão nosso sentido mais integrador, sua alteração pode afetar todos os aspectos de adaptação da criança ao seu meio ambiente ${ }^{6}$. Assim, a terapia ocupacional, como uma ciência com bases na ética e no saber, busca a participação ativa da criança na construção de sua identidade. Por meio da análise e seleção de materiais e atividades, sua atuação em intervenção precoce em deficientes visuais utiliza estratégias que facilitem o aprendizado de habilidades, fortaleçam a eficiência das funções essenciais para a adaptação ao meio, promovam e mantenham o crescimento, o desenvolvimento e a saúde.

\section{Considerações sobre o desenvolvimento da visão}

O desenvolvimento da visão, assim como o desenvolvimento de outras funções do organismo, é permeado por fatores de maturação neurológica e de aprendizagem. É determinado por fatores genéticos e influenciado por fatores ambientais ${ }^{7}$. Segundo Ciancia et $a l .{ }^{8}$, ao nascimento, os olhos estão geneticamente determinados para a visão normal, mas são necessárias experiências adequadas e oportunas para que as possibilidades genéticas possam se manifestar.

Inúmeras pesquisas, na década de 1960, abriram perspectivas para os estudos e determinação sobre os períodos críticos de maturação em diferentes regiões do sistema nervoso central. O desenvolvimento do sistema neurológico da visão foi, então, vastamente pesquisado.

Os estudos de Wiesel ${ }^{9}$ demonstraram que o primeiro ano de vida é crítico para o desenvolvimento das funções visuais, e a privação de estímulos visuais durante esse período pode provocar danos funcionais irreversíveis. Sabe-se, portanto, que há uma interrelação entre maturação neurológica e experiências ambientais, e uma favorece o desenvolvimento da outra. Assim, Lipsitt ${ }^{10}$ refere que os estímulos visuais recebidos do ambiente provocam modificações na maturação neurológica da visão. Essas modificações podem, por sua vez, alterar a habilidade do organismo em assimilar os estímulos que recebe do ambiente. Para Vilanova ${ }^{11}$, o processo de formação de sinapses e o de mielinização dependem de um componente biológico e de estímulos externos.

Durante as primeiras semanas de vida pós-natal, a retina, as vias ópticas e o córtex visual desenvolvem seus contatos celulares. À medida que chegam os estímulos visuais do ambiente, sinapses são realizadas pelas células neurais, favorecendo a função visual e tornando-a permanente ${ }^{12,13}$. A partir do nascimento, a criança usa a sua visão para aprender sobre o mundo e profundas mudanças estruturais ocorrem no sistema neurológico da visão, durante o primeiro ano de vida. Essas mudanças relacionam-se com o desenvolvimento das funções visuais e sua eficiência. Contudo, ao final do primeiro ano de vida, muitas sinapses foram eliminadas, sendo esse fato considerado um evento regressivo e altamente crítico para o desenvolvimento da visão ${ }^{14}$. Portanto, a estimulação visual que o lactente recebe a partir do nascimento é de fundamental importância para a formação de conexões neurais responsáveis pela visão.

Apesar de o primeiro ano de vida ser considerado crítico para o desenvolvimento da visão do bebê, ele continuará desenvolvendo-a e aprimorando-a durante os anos seguintes. As diferentes experiências sensoriomotoras que a criança vivencia contribuem de modo espontâneo para o desenvolvimento da visão. Conforme Hyvärinen ${ }^{12}$, a visão é aprendida e melhora seu funcionamento e eficiência com a utilização adequada.

\section{Características do desenvolvimento da criança com baix a visão}

Durante o primeiro ano de vida, inúmeras serão as transformações no desenvolvimento da criança, e em nenhum outro período da vida os saltos evolutivos ocorrerão com tão notável velocidade ${ }^{15}$.

Considerando a importância dos primeiros anos de vida para o desenvolvimento da criança, a deficiência visual pode, na maioria dos casos, comprometer em maior ou menor grau o desenvolvimento neuromotor, o desenvolvimento das habilidades das mãos, a cognição e a linguagem ${ }^{5,16,17}$.

$\mathrm{O}$ vínculo entre a mãe e a criança é um dos primeiros aspectos que podem ser afetados, comprometendo outras áreas do desenvolvimento. Sabe-se que as relações entre a mãe e a criança nos primeiros anos de vida têm a ver com o futuro desenvolvimento da personalidade de cada criança. Além disso, é a mãe que, com seu cuidado afetuoso no dia-a-dia, oferece à criança as primeiras oportunidades de experimentar o mundo que a rodeia. As sensações táteis do toque durante o banho e a troca de roupas, durante a amamentação, a fala e as cantigas, o contato de olho e o olhar recíproco são trocas iniciais que despertam o interesse da criança e a motivam para as interações com pessoas e objetos do meio ambiente. 
Contudo, o nascimento de uma criança deficiente gera uma série de mudanças nas relações familiares, que podem influenciar diretamente a relação que a mãe estabelece com seu filho. Os sentimentos gerados pelo nascimento de um filho, que não era o esperado, são profundos e variados, sendo mais freqüentes a negação, a rejeição, a culpa e a superproteção. Esses sentimentos podem, muitas vezes, fazer com que os pais demorem a procurar serviços de habilitação e, assim, deixem de receber as orientações e o apoio necessários. Muitos pais passam meses à procura de uma solução médica imediata, indo de consultório a consultório, negandose a entender que, em muitos casos, a intervenção precoce, aliada ao acompanhamento médico oftalmológico, pode ser o principal caminho para promover o desenvolvimento da criança.

Durante esse período de busca da cura, que pode não existir, muitas crianças deixam de receber a estimulação necessária em momentos oportunos para o desenvolvimento da visão. Esse fato pode acarretar atrasos no desenvolvimento de outras funções, como as motoras, cognitivas ou de linguagem, além de comprometer o desenvolvimento socioafetivo e favorecer o aparecimento de deficiências secundárias e comportamentos estereotipados. Esses comportamentos estereotipados ou maneirismos são freqüentemente observados em crianças com cegueira congênita. Porém, também são encontrados em crianças com baixa visão, principalmente naquelas que recebem pouca estimulação ambiental e, por este motivo, não utilizam seu corpo para explorar o ambiente nem suas mãos para manipular objetos. Essas crianças, com pouca solicitação ambiental, podem desenvolver os comportamentos de auto-estimulação, caracterizados como movimentos sem função, como balanceios corporais, movimentos rítmicos com as mãos realizando toques repetitivos sobre o próprio corpo, superfícies ou objetos, movimentos com a cabeça e fala fora de um contexto, entre outros.

Geralmente, a deficiência visual sem uma intervenção oportuna pode causar um empobrecimento das vivências pessoais, prejudicando as experiências sensoriomotoras, a manipulação e a exploração dos objetos, gerando atrasos na aquisição das habilidades que são mediadas pela visão.

\section{Objetivos}

A intervenção precoce em crianças com visão subnormal visa a criar condições de favorecimento para o pleno desenvolvimento das potencialidades de cada criança na faixa etária de 0 a 3 anos. Tem como princípio básico a atuação nos períodos de sensibilidade crítica para o seu desenvolvimento neuropsicomotor. Visa ainda à criação de um ambiente rico em estímulos adequados, dando-lhe a oportunidade de desenvolver e integrar todas as áreas do desenvolvimento.

\section{Intervenção}

A intervenção precoce em crianças com baixa visão destaca-se como sendo de importância fundamental, pois tem um caráter preventivo, ou seja, previne o aparecimento de deficiências secundárias. Na criança vidente, a visão é o agente desencadeador da motivação para a realização de movimentos e ações. A criança com deficiência visual necessita de intervenção para que sejam nela despertados o desejo, a curiosidade e a motivação para agir sobre o ambiente. Ela é importante ainda porque acontece no período em que ocorrem as maiores e mais significativas mudanças no desenvolvimento da criança, nos períodos mais curtos de tempo. Criança e família têm valor central na intervenção precoce.

A intervenção precoce inicia-se com a avaliação da criança. Essa avaliação deve combinar a avaliação funcional da visão e a avaliação do desenvolvimento global da criança, utilizando procedimentos formais e a observação do comportamento. É um processo dinâmico, realizado por equipe interdisciplinar, em situações lúdicas e de acordo com o perfil do desenvolvimento da criança.

A programação da habilitação é individualizada, de acordo com o resultado da avaliação, considerando as áreas do desenvolvimento que se encontram alteradas e as potencialidades de cada criança. Utilizam-se estratégias criando condições para o pleno desenvolvimento das capacidades da criança, prevenindo futuros déficits. Abrange todas as áreas do desenvolvimento infantil.

Os recursos utilizados são praticamente infinitos, pois a criança está em constante transformação, modificando as suas necessidades. O principal recurso utilizado é a atividade do brincar, mas principalmente o brincar participativo e prazeroso. Essa atividade é proposta de acordo com o perfil do desenvolvimento da criança. Adaptações como contraste, textura, odores, sons são necessárias em alguns materiais. O ambiente também poderá sofrer modificações de acordo com a patologia, os sinais e os sintomas, como no caso de crianças com fotofobia, que necessitam de ambiente pouco iluminado para que possam ser 
motivadas para o olhar. Em crianças com glaucoma, por exemplo, é preciso utilizar luz direta sobre o material a ser manipulado, ambiente pouco iluminado e objetos com pouca reflexibilidade.

As orientações fornecidas às famílias baseiam-se nas características e nas necessidades de cada criança. Orientações específicas estão sempre de acordo com o contexto socioeconômico e cultural em que está inserida a criança. As orientações fundamentam-se no desenvolvimento neuropsicomotor normal da criança, permitindo que utilize funcionalmente a visão e vivencie todas as etapas do desenvolvimento.

A intervenção precoce segue alguns princípios básicos:

- Estimular a eficiência visual.

- Favorecer o uso funcional da visão em todas as situações do dia-a-dia, por menor que seja o resíduo visual.

- Favorecer o estabelecimento da relação mãecriança.

- Proporcionar atividades funcionais que integrem as sensações captadas pelos órgãos dos sentidos com as funções psicomotoras.

- Criar condições para a construção do universo sensoriomotor.

\section{Considerações finais}

A intervenção precoce em crianças com visão subnormal, visando ao desenvolvimento máximo da visão, requer longo tempo de seguimento, muita dedicação e grande colaboração entre pais e terapeutas. $\mathrm{O}$ primeiro passo é a formação do vínculo com a família, estabelecendo uma parceria, com um fim único - favorecer o desenvolvimento da criança e o uso funcional da visão.

\section{SUMMARY}

\section{Early intervention in the child with low vision}

The present work discusses the development of vision considering the environmental and neurological maturation factors. It contemplates the low vision children's development characteristcs and the areas of the development that can be commited for visual alterations. It presents an approach of the occupational therapy performance in early intervention, relating the fundamental presuppositions for intervention with those children.

\section{Keyw ords}

Low vision, early intervention, occupational therapy.

\section{Referências}

1. Temporini ER \& Kara-José N. Níveis de prevenção de problemas oftalmológicos: propostas de investigação. Arq Bras Oftal, 58:189-92, 1995.

2. Botega MBS \& Gagliardo HGRG. Intervenção precoce na deficiência visual: o que fazemos? Revi Soc Bras Fonoaudiol, 2(Supl.1):46-50, 1998.

3. Sanchez PA. Deficiencias visuales y psicomotricidade: teoria y pratica. Organización Nacional de Ciegos Españoles, 1994, 255p.

4. Sonksen PM, Petrie A, Drew KJ. Promotion of visual development of severely visually impaired babies: evaluation of a developmentally based programe. Dev Med Child Neurol, 33:320-35, 1991.

5. Gagliardo HGRG \& Gonçalves VMG. Proposta metodológica para detecção de alterações no comportamento visual de lactentes. Arq Bras Oftal, 63:59, 2000.

6. Hyvärinen L. Considerations in evoluation and treatment of the child with low vision. Americ J Occupational Therapy, 59:891-7, 1995.

7. Brandão JS. Desenvolvimento psicomotor da mão. Rio de Janeiro, Enelivros, 1984, 453p.

8. Ciancia AO, Fiondella AM, Penerini YP. La estimulación temprana en oftalmologia. Arq Bras Oftal, 49:147-9, 1986.

9. Wiesel TN. The postnatal development of the visual cortex and the influence of environmemt. (Nobel Lecture). Biosci Rep, 2:351-77, 1982.

10. Lipsitt LP. Learning in infancy: cognitive development in babies. J Pediatr, 109: 172-82, 1986.

11. Vilanova LCP. Aspectos neurológicos do desenvolvimento do comportamento da criança. Rev Neurociências, 6:106-10, 1998.

12. Hyvärinen, L. La vision normal y anormal en los ninos. Madri, Organizacion Nacional de Ciegos Españoles, 1988, 92p

13. Alves MR \& Kara-José N. O olho e a visão. Rio de Janeiro, Vozes, 1996, 151p.

14. Huttenlocher PR. Morphometric study of human cerebral cortex development. Neurophych, 28:517-27, 1990.

15. Diament AJ. Exame neurológico do lactente. In: Diament AJ \& Cypel S. Neurologia infantil. 3. ed., São Paulo, Atheneu, 1996, pp. 35-62.

16. Jan JE, Sikanda A, Groenveld M. Habilitation and rehabilitation of visually impaired and blind children. Pediatrician, 17:202-97, 1990

17. Gonçalves VMG \& Gagliardo HGRG. Aspectos neurológicos do desenvolvimento do lactente com baixa visão. Temas sobre Desenvolvimento, 7:33-9, 1998.

\section{Endereço para correspondência:}

Heloisa G. R. Gardon Gagliardo

Centro de Estudos e Pesquisas em Reabilitação "Prof. Dr. Gabriel de O. S. Porto" - Faculdade de Ciências Médicas da Universidade Estadual de Campinas Av. Adolfo Lutz, s/n

Cidade Universitária Zeferino Vaz CEP 13084-880 - Campinas, SP 